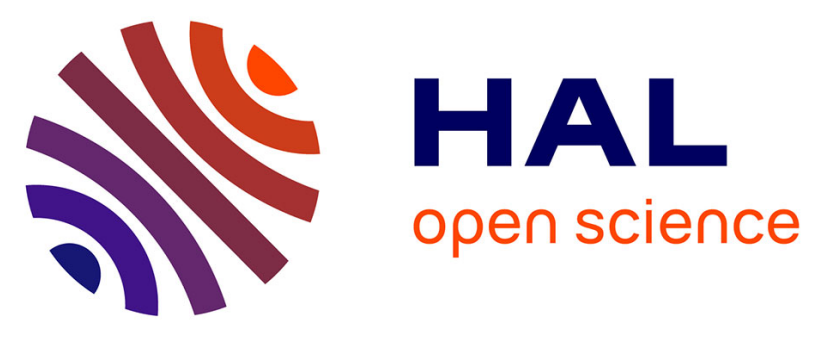

\title{
Structure, biosynthesis, and properties of kurstakins, nonribosomal lipopeptides from Bacillus spp.
}

Max Béchet, Thibault Caradec, Walaa Hussein, Ahmed Abderrahmani, Marlène Chollet, Valérie Leclère, Thomas Dubois, Didier Lereclus, Maude Pupin, Philippe Jacques

\section{To cite this version:}

Max Béchet, Thibault Caradec, Walaa Hussein, Ahmed Abderrahmani, Marlène Chollet, et al.. Structure, biosynthesis, and properties of kurstakins, nonribosomal lipopeptides from Bacillus spp.. Applied Microbiology and Biotechnology, 2012, 95 (3), pp.593-600. 10.1007/s00253-012-4181-2 . hal00749819

\section{HAL Id: hal-00749819 https://hal.science/hal-00749819}

Submitted on 8 Nov 2012

HAL is a multi-disciplinary open access archive for the deposit and dissemination of scientific research documents, whether they are published or not. The documents may come from teaching and research institutions in France or abroad, or from public or private research centers.
L'archive ouverte pluridisciplinaire $\mathbf{H A L}$, est destinée au dépôt et à la diffusion de documents scientifiques de niveau recherche, publiés ou non, émanant des établissements d'enseignement et de recherche français ou étrangers, des laboratoires publics ou privés. 
1 Structure, Biosynthesis and Properties of Kurstakins, NonRibosomal

3 Max Béchet $^{\mathrm{a}}$, Thibault Caradec ${ }^{\mathrm{a}}$, Walaa Hussein ${ }^{\mathrm{a}}$, Ahmed Abderrahmani ${ }^{\mathrm{b}}$,

4 Marlène Chollet $^{\mathbf{a}}$, Valérie Leclère ${ }^{\mathbf{b}}$, Thomas Dubois $^{\mathbf{c}}$, Didier Lereclus ${ }^{\mathbf{c}}$,

6 a'Laboratoire des Procédés Biologiques, Génie Enzymatique et Microbien (ProBioGEM),

7 UPRES-EA 1026, Polytech'Lille/IUT A, Université Lille Nord de France, Avenue Paul Langevin, F-59655 Villeneuve d'Ascq Cedex, France

9 baboratoire de Biologie Cellulaire et Moléculaire, Faculté des Sciences Biologiques,

10 Université des Sciences et de la Technologie Houari Boumediene, B.P. 32, El Alia, Alger,

Algérie

'INRA, UMR1319 Micalis, La Minière, F-78280 Guyancourt, France

13 'LIFL, UMR USTL/CNRS 8022, INRIA Lille-Nord Europe, F-59655 Villeneuve d'Ascq

15

16

17

18Running title: Kurstakins

19

20Keywords: kurstakins, lipopeptides, Bacillus cereus, Bacillus thuringiensis, NRPS, spreading 21

$22 *$ Correspondance to: Dr Philippe Jacques, Laboratoire des Procédés Biologiques, Génie 23Enzymatique et Microbien, UPRES-EA 1026, Polytech'Lille/IUT A, Université Lille Nord de 24France - Sciences et Technologies, USTL, Avenue Paul Langevin, F-59655 Villeneuve 25 d'Ascq Cedex, France

26Tel: +33328767440, Fax +33328767356 (e-mail: philippe.jacques@polytech-lille.fr) 


\section{Abstract}

28 A new family of lipopeptides produced by Bacillus thuringiensis, the kurstakins, was 29discovered in 2000 and considered as a biomarker of this species. Kurstakins are 30lipoheptapeptides displaying antifungal activities against Stachybotrys charatum. Recently, 31the biosynthesis mechanism, the regulation of this biosynthesis and the potential new 32 properties of kurstakins were described in the literature. In addition, kurstakins were also 33 detected in other species belonging to Bacillus genus such as Bacillus cereus. This mini34review gathers all the information about these promising bioactive molecules. 


\section{Introduction}

Between 1949 and 1986, three different families of nonribosomal lipopeptides were

38identified in Bacillus spp.: surfactins, iturins and fengycins (Jacques, 2011). A new family 39produced by Bacillus thuringiensis and named the kurstakins, was discovered in 2000. The 40recent characterization of the biosynthesis mechanism of these compounds (in 2009 and 412011), their main properties (in 2011 and 2012) and the regulation of their biosynthesis in 422012, open new perspectives for these lipopeptidic compounds. This mini-review is the first 43one dedicated to them.

\section{Discovery, structure and mass spectrometry detection}

Among the spores from six ATCC Bacillus thuringiensis strains, the presence of a 46lipophilic biomarker, named kurstakin, was detected for the first time from the $B$. 47thuringiensis subsp. kurstaki strain HD-1 (Hathout et al. 2000). After a spore washing, the 48authors identified using LC-MS four $[\mathrm{M}+\mathrm{H}]^{+}$molecular ions of $m / z 879,893,893$ and 907 49(with a common fragment ion at $\mathrm{m} / \mathrm{z}$ of 609 ). The molecular masses of these four compounds 50differed by $14 \mathrm{Da}\left(-\mathrm{CH}_{2}-\right)$, suggesting that these molecules were homologous lipopeptides. 51Further acid hydrolysis led to the identification of the corresponding free fatty acids from the 52four compounds which are 9-methyldecanoic, dodecanoic, 10-methylundecanoic and 1153methyldodecanoic acids, generating kurstakins $\mathrm{C}_{11}$ (iso-), $\mathrm{C}_{12}$ (n- and iso-) and $\mathrm{C}_{13}$ (iso-), 54respectively. Amino acid analyses revealed the same residues for the four molecules: Thr, 55His, Ala, Gly, Ser and Glx (Gln or Glu) with molar ratios of 1:1:1:1:1:2. The ascertainment of 56the chemical structures of the kurstakins was completed by the determinations of (i) the 57sequence of the heptapeptide: Thr-Gly-Ala-Ser-His-Gln-Gln; (ii) the presence of an amide 58bond between the fatty acid chain and the first threonine residue and (iii) the presence of a 59lactone linkage between the serine at position 4 and the $\mathrm{C}$ terminus of glutamine at position 7 
60(Fig. 1). Such a peculiar lactone ring between the fourth and seventh amino acids of the 61peptidic part was recently reported for a new biosurfactant (licheniformin) produced by 62Bacillus licheniformis MS3 (Biria et al. 2010). However, neither the nonribosomal peptide 63synthesis statute of kurstakins in B. thuringiensis subsp. kurstaki strain HD-1 nor the possible 64occurrence of D- forms among the seven amino acids of their peptidic moiety (compared to 65other known nonribosomal lipopeptides from Bacillus spp.) were demonstrated. Three years 66later, a homologous series of three ions at $\mathrm{m} / \mathrm{z} 892,906$, and 920 similar to those of kurstakins 67was detected by Madonna et al. (2003) in Bacillus subtilis ATCC 6051 but these results were 68 not confirmed by genetic analyses (see below). Another study dealing with numerous Bacillus 69sp. strains isolated worldwide further revealed the presence of kurstakins in 20 from 54 strains 70tested, using MALDI-TOF-MS fingerprinting of whole bacterial cells (Price et al. 2007). 71These were typically identified by the molecular ions of $\mathrm{m} / z 889,905,917$, and 933 but their 72primary structures or those of other putative kurstakins of $\mathrm{m} / \mathrm{z}$ about 942 and 958 were not 73elucidated. The authors confirmed that these secondary metabolites were retained by the 74 spores or cells and not secreted because they predominantly found them in the bacterial 75 colonies on agar plates.

76 New information about the structural diversity of the kurstakins was recently reported 77by MALDI-TOF-MS analyses of the Bacillus sp. strain NK2018 (Bumpus et al. 2009) and six 78B. thuringiensis strains (Abderrahmani et al. 2011). From culture supernatants of strain 79NK2018 grown in an M9 minimal medium, the first authors showed the presence of six 80kurstakin variants in differing amounts, with molecular masses ranging from 907.4765 to 81953.5192 Da (formulae from $\mathrm{C}_{40} \mathrm{H}_{65} \mathrm{O}_{13} \mathrm{~N}_{11}$ to $\mathrm{C}_{42} \mathrm{H}_{71} \mathrm{O}_{14} \mathrm{~N}_{11}$ ), corresponding to kurstakins with 82a $\beta$-hydroxylated fatty acid chain with 12,13 and 14 atoms of carbon. The occurrence of three 83 molecules differing by exactly $18.0103 \mathrm{Da}$ from three other ones was attributed to the 84 presence or lack of a lactone ring inside the peptidic part of the molecules, suggesting that 
85kurstakins might be found currently in culture supernatant as variants with linear peptidic 86parts. After growth on either AK or LB medium, Abderrahmani et al. (2011) detected the 87presence of the three $\mathrm{C}_{11}, \mathrm{C}_{12}$ and $\mathrm{C}_{13}$ kurstakin isoforms in six B. thuringiensis strains from 88the 11 tested. Some other molecular ions with $\mathrm{m} / \mathrm{z}$ of 920,942 and 958 were also sometimes 89detected and could correspond to the kurstakin with a $\mathrm{C}_{14}$ fatty acid chain (Abderrahmani 902011). To summarize, the kurstakins synthesized by Bacillus spp. consist of lipoheptapeptides 91which (i) are linked to between $\mathrm{C}_{11}$ and $\mathrm{C}_{14}$ fatty acids, $\beta$-hydroxylated or not, with two 92isoforms (n-, iso-); (ii) are partially cyclic (lactone bond between Ser/4 and C-terminal Gln/7) 93and might even be linear; and (iii) are expected to contain two D-configured amino acids. In 94MALDI-TOF-MS experiments, the values of the $[\mathrm{M}+\mathrm{H}]^{+},[\mathrm{M}+\mathrm{Na}]^{+}$and $[\mathrm{M}+\mathrm{K}]^{+}$molecular 95ions detected should range from 878.473 (cyclic $\mathrm{C}_{11}$ isoform $[\mathrm{M}+\mathrm{H}]^{+}$) to $992.481 \mathrm{Da}$ (linear 96 $\beta$-hydroxylated $\mathrm{C}_{14}$ isoform $[\mathrm{M}+\mathrm{K}]^{+}$), under conditions allowing these biomarkers to be 97detected (Figs. 1 and 2).

\section{Biosynthesis}

The operons potentially encoding kurstakin synthetases in $B$. cereus and $B$.

100thuringiensis were identified by bioinformatics analyses using two new approaches. In the 101 first one, Bumpus et al. (2009) took advantage of the size of the NRPS enzymes and the 102presence of unique marker ions derived from the common phosphopantetheinyl cofactor to 103adapt mass spectrometry-based proteomics to detect selectively NRPS and PKS gene clusters 104in microbial proteomes without requiring genome sequence information. In these conditions, 105the authors highlighted in strains Bacillus sp. NK2018 and Bacillus cereus AH1134 the genes 106involved in the biosynthesis of the kurstakins. The second approach used PCR with 107degenerate primers based on the intraoperon DNA sequence alignment of adenylation and 108thiolation domains of all enzymes implicated in the biosynthesis of the lipopeptide family 
109(Tapi et al. 2010). Two sets of primers elaborated from first bacillomycin genes, then from 110kurstakin genes led to the discovery of genes implied in kurstakin biosynthesis (Tapi 2010; 111Tapi et al. 2010; Abderrahmani et al. 2011). From these two studies the organization of the 112 kurstakin cluster could be predicted. This cluster (Fig. 3) contains three genes ( $k r s A, k r s B$ and $113 \mathrm{krsC}$ ) which encode three large multifunctional proteins (KrsA, KrsB and $\mathrm{KrsC}$ ) constituting 114the complete synthetase. This latter is organized as follows: KrsA comprises one module 115(m1), $\mathrm{KrsB}$ is constituted of two modules ( $\mathrm{m} 2$ and $\mathrm{m} 3$ ) and $\mathrm{KrsC}$ includes four modules (m4 116to $\mathrm{m} 7$ ) and for each module a condensation-adenylation-thiolation motif can be found. In 117addition, $\mathrm{m} 1$ and $\mathrm{m} 6$ harbour a supplementary epimerization domain. The module 7 includes a 118final thioesterase domain enabling the unhooking of the neo-formed peptide from the NRPS 119and its possible cyclization. The combination of the predictions obtained from different 120bioinformatics tools (Ansari et al. 2004; Raush et al. 2005; Bachmann and Ravel 2009) led to 121a peptide with the primary structure: D-Thr_Gly/Ala/Gln/Glu_Ala_Ser_X_D-Gln_Gln.

122 While the precise mechanism of biosynthesis was not yet experimentally analysed, it 123 could easily be deduced from the bioinformatics analysis and the high quantity of available 124information on the biosynthesis of other lipopeptides from Bacillus or Pseudomonas species 125(Sieber and Marahiel, 2005; Raaijmakers et al. 2010; Roongsawang et al. 2010) (Fig. 3). The 126first synthetase, KrsA, contains one module with a starting condensation domain (Rausch et 127al. 2007; Kraas et al. 2010) which catalyses the link between a fatty acid chain of different 128length and isomery and a threonine residue activated by the adenylation domain and 129covalently fixed to the thiolation domain of this first module. The last domain of this first 130module is an epimerization domain that will transform the L-Thr to D-Thr. The second 131synthetase, $\mathrm{KrsB}$, contains two modules responsible for the activation and the incorporation of 132two other amino acid residues, Gly and Ala. In the third synthetase, $\mathrm{KrsC}$, four modules are 133involved in the incorporation of the four other amino acid residues: Ser, His, Gln and Gln. 
134The presence of an epimerization domain in the third module probably modifies the 135incorporated L-Gln to form the D-configuration. The last module contains a thioesterase 136which will catalyse the liberation of the peptide and probably its partial cyclization (Kopp and 137Marahiel 2007). A gene encoding a phosphopantetheinyl transferase was identified 138downstream from the NRPS complex. This enzyme could be involved in the transformation of 139the apo-form of the enzymes to the holo-form by the addition of a phosphopantetheinyl group 140 from the coenzymeA to the different thiolation domains (Mofid et al. 2004). A second 141thioesterase (TEII) is encoded by the next gene $(k r s D)$. The results obtained by Schwarzer et 142al. (2002) on the biochemical characterization of two second similar thioesterases named TEII 143and involved in the surfactin and bacitracin peptide antibiotics biosynthesis showed that these 144enzymes play a role in the regeneration of the misacylated Peptidyl Carrier Proteins 145(Thiolation domains). The presence of linear peptide in strain NK2018 could result from the 146action of this second thioesterase or an insufficient expression or efficacy of the first one.

A sixth gene $(k r s E)$ situated upstream from the $k r s A-C$ genes and belonging to the 148kurstakin cluster was identified by Dubois et al. (2012) in Bacillus thuringiensis Bt407. The 149product of this gene, the protein KrsE, is a presumed efflux protein and could be involved in 150the secretion of the lipopeptide.

\section{Overview on kurstakin potentially producing microorganisms}

152 In order to identify the genetic potential for kurstakin production among 153microorganisms, we performed a BLASTp method using $\mathrm{KrsA}, \mathrm{KrsB}, \mathrm{KrsC}, \mathrm{KrsD}, \mathrm{KrsE}$ and 154Ppant sequences from $B$. thuringiensis serovar pondicheriensis BGSC 4BA1 as queries. The 155same cluster leading to kurstakin synthesis was retrieved in the genome of 32 strains for 156which genomes are sequenced, assembled and either finished or still as drafts (V. Leclère, M. 157Pupin, W. Hussein, P. Jacques, unpublished data). Without exception, all the strains pointed 
158out belong to the Bacillus genus, more especially to the B. cereus species group, indicating 159that kurstakin production could be considered as the marker for this group. However, no 160sequences of kurstakin synthetases were present in Bacillus anthracis and Bacillus 161cytotoxicus although they belong to the same B. cereus group. However, only one genome is 162available for B. cytotoxicus and five genomes are completely sequenced and assembled for 163B. anthracis. So the question of lack of kurstakin synthetase in the B. anthracis species 164remains open and should be related later to the high virulence of the strains. In addition, 165kurstakins were also detected in B. subtilis ATCC 6051 strain (Madonna et al. 2003). This 166strain was an ancestor of the reference strain 168 (Zeigler et al. 2008), the genome of which 167 was completely sequenced and, surprisingly, no traces of kurstakin genes were found in this 168genome. The kurstakin cluster is present in most of the genomes of $B$. cereus and $B$. 169thuringiensis for which genomic data are available (Table 1). Kurstakin genes were also 170detected in the partially sequenced genome of B. cereus BDRD-Cer4 and B. cereus AH1134. 171 When the sequences are present in the genomes, they are highly conserved and the 172organization of the cluster (KrsE-KrsA-KrsB-KrsC-Ppant-TE) is also conserved. However, 173the strains B. cereus AH603, BDRD-ST196, B. mycoides DSM 2048 and $B$. 174weihenstephanensis KBAB4 might produce a variant form with a Glu or Asp instead of Gln at 175the last position as predicted by NRPSpredictor2 (Röttig et al. 2011). As no amino acid 176residue can be predicted for module 6, the strain B. cereus Rock4-2 can be supposed to 177 produce another member of the kurstakin family varying by the residue at this position..

\section{Regulation}

179 The regulation system of kurstakin production has been partially described in Bacillus 180thuringiensis Bt407 (Fig. 4). A transcriptomic analysis indicates that the four genes krsEABC 181 form a cluster whose transcription is activated by the NprR-NprX quorum-sensing system 182during late stationary phase (Dubois et al. 2012). NprR is a quorum sensor activated by its 
183cognate signaling peptide, NprX. NprR-NprX functions as a typical Gram-positive quorum184sensing system: the pro-signaling peptide NprX is exported from the bacterial cell and after 185 being processed to its active form (presumably a heptapeptide), the peptide is reimported into 186the bacteria, where it binds to NprR allowing the recognition of its DNA target (Perchat et al. 1872011). 189 groups. The first group is composed of genes coding for stress resistance proteins, including 190cytochrome P450, cysteine dioxygenase and several metabolite exporters. The second group 191is composed of four genes encoding the Opp permease system, involved in the import of 192small peptides into the cells. The third group is composed of the NRPS krs genes. The last 193 group codes for degradative enzymes and proteins able to bind organic material (Dubois et al. 1942012).

\section{Properties}

196 Kurstakins are not recovered in the culture supernatant of producing strains but are 197 found in association with the bacterial cells and particularly on spores (Hathout et al. 2000; 198Price et al. 2007; Abderrahmani et al. 2011). However, co-infection experiments carried out 199with a producing strain and a non-producing one in the insect larvae Galleria mellonella, 200suggest that this molecule is secreted (Dubois et al. 2012). This apparent discrepancy between 201these results suggests that kurstakin is a secreted molecule with a high affinity for membranes. 202This high affinity could be due to the presence of the basic amino acid histidine which confers 203a cationic charge to the lipopeptide and thus facilitates its electrostatic interaction with 204phospholipids of the cell membrane.

205 Purified kurstakins displayed an antifungal activity against Stachybotrys charatum, 206showing a halo of inhibition identical to the one obtained with polymyxin B used as positive 
207control (Hathout et al. 2000). Nevertheless, Abderrahmani et al. (2011) showed that no 208correlation exists between the antifungal activities of the strains and the presence of 209kurstakins. Indeed, some producing strains did not show any antifungal activity whereas some 210 other ones did not produce kurstakin and showed antifungal properties. However, their 211evaluation was made with the fungi Mucor rouxii DSM 1191, Rhizopus orizae DSM 907, 212Penicillium roqueforti DSM 1080, Aspergillus niger DSM 737, and Fusarium oxysporum 213DSM 62297, different from those used by Hathout et al. These data indicate that kurstakin 214 might be a pore-forming molecule with a limited spectrum of activity.

215 The fact that significant colonization of solid media was detected neither for non216producing kurstakin strains nor for a kurstakin-deficient mutant indicates that kurstakins are 217responsible for the invasive growth (Abderrahmani et al. 2011). Moreover, a strain where the 218genes $k r s \mathrm{~A}, k r s \mathrm{~B}$ and $k r s \mathrm{C}(\Delta k r s \mathrm{ABC})$ were deleted was unable both to swarm and to form a 219biofilm at the air/liquid interface (Dubois et al. 2012). A very interesting property of kurstakin 220 is its ability to enhance the survival of $B$. thuringiensis in the insect cadaver (Dubois et al. 2212012). In view of these various properties, kurstakin might allow B. thuringiensis to spread 222across the cadaver, thereby facilitating access to new substrates and increasing its ability to 223disseminate in the environment.

\section{Perspectives}

225 The research on this fourth family of lipopeptides produced by Bacillus spp. has yet to 226be developed, and several perspectives are worth considering. The precise structure of the 227different variants should be confirmed by chemical analysis: the presence of the D-amino acid 228residues should be validated by analysis of amino acid residues after acid hydrolysis and 229derivatization, e.g., by GC using chirasyl-L-Val column. Confirmation of the presence of 230linear structure or C14 fatty acid chain should be done by LC-MS-MS analysis and NMR. 231The predicted biosynthetic pathway proposed in this review should be confirmed by 
232 biochemical analysis of the different domains of the synthetase. Particular attention will have 233to be paid to the thioesterase domains and their role in the concomitant presence of cyclized 234and linear forms of the lipopeptides.

235 Hathout et al. (2000) have evaluated the amount of kurstakin produced at about 15-20 $236 \mu \mathrm{g} / \mathrm{mg}$ of spore. Overproducing mutant cells could be constructed using similar strategies 237developed by Leclère et al. (2005), Fickers et al. (2009) and Coutte et al. (2010), for the 238overproduction of other families of lipopeptides from B. subtilis. Purification techniques need 239to be developed to extract the lipopeptides or collect them in the supernatant.

240 Lipopeptides from Bacillus spp. are well known for their potential applications in 241several fields (Jacques, 2011) including biocontrol of plant pathogens (Ongena and Jacques, 2422008). Purified compounds could be thus used in different physico-chemical or biological 243tests in order to characterize their physico-chemical properties and biological activities and 244their potential applications.

\section{Acknowledgements}

246 This work received financial support from the Université Lille 1, Sciences et 247Technologies and ARCIR funds from Nord-Pas-de-Calais and the European Funds of 248INTERREG IV PhytoBio Project. We acknowledge William Everett for his kind English 249proof reading.

\section{References}

252Abderrahmani A, Tapi A, Nateche F, Chollet M, Leclère V, Wathelet B, Hacene H, Jacques P 253(2011) Bioinformatics and molecular approaches to detect NRPS genes involved in the 254biosynthesis of kurstakin from Bacillus thuringiensis. Appl Microbiol Biotechnol 92:571-581 
256Abderrahmani A (2011) Identification du mécanisme de synthèse non ribosomique d'un 257nouveau lipopeptide, la kurstakine et étude de son influence sur le phénotype de souches de 258Bacillus thuringiensis isolées en Algérie. Thèse de Doctorat d'Etat, Université des Sciences et 259de la Technologie Houari Boumediene, Alger, Algérie

260

261Ansari MZ, Yadav G, Gokhale, RS, Mohanty D (2004) NRPS-PKS: a knowledge-based 262resource for analysis of NRPS/PKS megasynthases. Nucleic Acids Res 32:405-413

263

264Bachmann BO, Ravel J (2009) Methods for in silico prediction of microbial polyketide and 265nonribosomal peptide biosynthetic pathways from DNA sequence data. Methods Enzymol 266458:181-217

267

268Biria D, Maghsoudi E, Roostaazad R, Dadafarin H, Sahebghadam Lotfi A, Amoozegar MA 269(2010) Purification and characterization of a novel biosurfactant produced by Bacillus 270licheniformis MS3. World J Microbiol Biotechnol 26:871-878

271

272Bumpus SB, Evans BS, Thomas PM, Ntai I, Kelleher NL (2009) A proteomics approach to 273discovering natural products and their biosynthetic pathways. Nat Biotechnol 27:951-956 274

275Coutte F, Leclère V, Béchet M, Guez JS, Lecouturier D, Chollet-Imbert M, Dhulster P, 276Jacques P (2010) Effect of pps disruption and constitutive expression of srfA on surfactin 277productivity, spreading and antagonistic properties of Bacillus subtilis 168 derivatives. J Appl 278Microbiol 109:480-491 
280Dubois T, Faegri K, Perchat S, Lemy C, Buisson C, Nielsen-LeRoux C, Gohar M, Jacques P, 281Ramarao N, Kolsto AB, Lereclus D (2012) Necrotrophism is a quorum-regulated lifestyle in 282Bacillus thuringiensis. PloS Pathogens 8:e1002629

283

284Fickers P, Guez JS, Damblon C, Leclère V, Béchet M, Jacques P, Joris B (2009) High-level 285biosynthesis of the anteiso-C(17) isoform of the antibiotic mycosubtilin in Bacillus subtilis 286and characterization of its candidacidal activity. Appl Environ Microbiol 75:4636-4640 287

288Hathout Y, Ho YP, Ryzhov V, Demirev P, Fenselau C (2000) Kurstakins: a new class of 289lipopeptides isolated from Bacillus thuringiensis. J Nat Prod 63:1492-1496

290

291Jacques P (2011) Surfactin and other lipopeptides from Bacillus spp. In: Soberon-Chavez G 292(ed) Biosurfactants microbiology monographs, Volume 20, Springer-Verlag, Berlin 293Heidelberg, pp 57-91

294

295Kopp F, Marahiel MA (2007) Macrocyclization strategies in polyketide and nonribosomal 296peptide biosynthesis. Nat Prod Rep 24:735-749

297

298Kraas FI, Helmetag V, Wittman M, Strieker M, Marahiel MA (2010) Functional dissection of 299surfactin synthetase initiation module reveals insights into the mechanism of lipoinitiation. 300Chem Biol 17:872-880

301

302Leclère V, Béchet M, Adam A, Guez JS, Wathelet B, Ongena M, Thonart P, Gancel F, 303Chollet-Imbert M, Jacques P (2005) Mycosubtilin overproduction by Bacillus subtilis 
304BBG100 enhances the organism's antagonistic and biocontrol activities. Appl Environ 305Microbiol 71:4577-4584

306

307Madonna AJ, Voorhees KJ, Taranenko NI, Laiko VV, Doroshenko VM (2003) Detection of 308cyclic lipopeptide biomarkers from Bacillus species using atmospheric pressure matrix309assisted laser desorption/ionization mass spectrometry. Anal Chem 75:1628-1637

310

311Mofid MR, Finking R, Essen L, Marahiel MA (2004) Structure-based mutational analysis of 312the 4'-phosphopantetheinyl transferases Sfp from Bacillus subtilis: carrier protein recognition 313and reaction mechanism. Biochemistry 14:4128-4136

314

315Ongena M, Jacques P (2008) Bacillus lipopeptides: versatile weapons for plant diseases 316biocontrol. Trends Microbiol 16:115-125

317

318Perchat S, Dubois T, Zouhir S, Gominet M, Poncet S, Lemy C, Aumont-Nicaise M, 319Deutscher J, Gohar M, Nessler S, Lereclus D (2011) A cell-cell communication system 320regulates protease production during sporulation in bacteria of the Bacillus cereus group. Mol 321Microbiol 82:619-633

322

323Price NP, Rooney AP, Swezey JL, Perry E, Cohan FM (2007) Mass spectrometric analyses of 324lipopeptides from Bacillus strains isolated from diverse geographical locations. FEMS 325Microbiol Lett 271:83-89

326 
327Raaijamakers JM, De Bruijn I, Nybroe O, Ongena M (2010) Natural functions of lipopeptides 328from Bacillus and Pseudomonas: more than surfactants and antibiotics. FEMS Microbiol Rev 32934:1037-1062

330

332Rausch C, Weber T, Kohlbacher O, Wohlleben W, Huson DH (2005) Specificity prediction of 333adenylation domains in nonribosomal peptide synthetases (NRPS) using Transductive Support 334Vector Machines (TSVM). Nucl Acids Res 33:5799-5808

335

336Rausch C, Hoof I, Weber T, Wohlleben W, Huson DH (2007) Phylogenetic analysis of 337condensation domains in NRPS sheds light on their functional evolution. BMC Evol Biol 7:78 338

339Roongsawang N, Washio K, Morikawa M (2010) Diversity of nonribosomal peptide 340synthetases involved in the biosynthesis of lipopeptide biosurfactants. Int J Mol Sci 12:141341172

342

343Röttig M, Medema MH, Blin K, Weber T, Rausch C, Kohlbacher O (2011) NRPSpredictor2-a 344web server for predicting NRPS adenylation domain specificity. Nucl Acids Res 39 (Web 345Server issue):W362-367

346

347Schwarzer D, Mootz HD, Linne U, Marahiel MA (2002) Regeneration of misprimed 348nonribosomal peptide synthetases by type II thioesterases. Proc Natl Acad Sci USA 99:1408334914088 
351Sieber SA, Marahiel MA (2005) Molecular mechanisms underlying nonribosomal peptide 352synthesis: approaches to new antibiotics. Chem Rev 105:715-738

353

354Tapi A (2010) Stratégie moléculaire de mise en évidence de peptides actifs d'origine non 355ribosomiale chez Bacillus sp. et Lactobacillus sp. PhD thesis, Université Lille1 Sciences et 356Technologies, France

357

358Tapi A, Chollet-Imbert M, Scherens B, Jacques P (2010) New approach for the detection of 359non ribosomal peptide synthetase genes in Bacillus strains by polymerase chain reaction. Appl 360Microbiol Biotechnol 85:1521-1531

361

362Zeigler DR, Pragai Z, Rodriguez S, Chevreux B, Muffler A, Albert T, Bai R, Wyss M, 363Perkins JB (2008) The origins of 168, W23, and other Bacillus subtilis legacy strains. J 364Bacteriol 190:6983-6995 
Table 1 Presence of kurstakin genes in sequenced genomes of B. cereus and B. thuringiensis

\begin{tabular}{|c|c|c|c|c|c|c|c|}
\hline \multirow[t]{2}{*}{ Strains } & \multirow[t]{2}{*}{ Sequenced genome status $^{1}$} & \multicolumn{6}{|c|}{ Genes $^{2}$} \\
\hline & & $k r s E$ & $k r s A$ & $k r s B$ & $k r s C$ & $s f p$ & $k r s D$ \\
\hline Reference strain: Bacillus thuringiensis serovar pondicheriens is BGSC $4 \mathrm{BA} 1$ & $\mathrm{C}$ & + & + & + & + & + & + \\
\hline \multicolumn{8}{|l|}{ B. thuringiensis } \\
\hline BMB171; sv chinens is CT-43 & $\mathrm{C}$ & + & + & + & + & + & + \\
\hline sv finitimus; sv konkukian str. 97-27; str.Al Hakam & $\mathrm{C}$ & - & - & - & - & - & - \\
\hline $\begin{array}{l}\text { Bt407; IBL 200; sv berliner ATCC 10792; sv huazhongensis BGSC 4BD1; sv kurstaki } \\
\text { str. T03a001; sv thuringiensis str. T01001; sv pakistani str. T13001; sv puls iensis } \\
\text { BGSC 4CC1; sv sotto str. T04001 }\end{array}$ & $\mathrm{U}$ & + & + & + & + & + & + \\
\hline IBL 4222 & $\mathrm{U}$ & + & + & + & TCT ? & + & + \\
\hline \multicolumn{8}{|l|}{ B. cereus } \\
\hline ATCC 14579; B4264; G9842 & $\mathrm{C}$ & + & + & + & + & + & + \\
\hline 03BB102; AH187; AH820; ATCC10987; E33L; Q1; bv anthracis str.CI & $\mathrm{C}$ & - & - & - & - & - & - \\
\hline 172560W; ATCC 10876; BDRD-ST24; BGSC 6E1; F65185; m1550; Rock1-15; Rock1-3 & $\mathrm{U}$ & + & + & + & + & + & + \\
\hline BDRD-Cer4 & $\mathrm{P}$ & + & + & + & + & + & + \\
\hline AH1134 & $\mathrm{P}$ & + & + & NF & + & $\mathrm{NF}$ & $\mathrm{NF}$ \\
\hline AH603; BDRD-ST196 & $\mathrm{U}$ & + & + & + & $7-\mathrm{D} / \mathrm{E}$ & + & + \\
\hline AH621 & $\mathrm{U}$ & + & $\mathrm{NF}$ & $\mathrm{NF}$ & TCT ? & + & $\mathrm{NF}$ \\
\hline AH676 & $\mathrm{U}$ & + & + & + & + & + & $\mathrm{NF}$ \\
\hline Rock4-2 & $\mathrm{U}$ & + & + & + & $6-X$ & + & + \\
\hline \multicolumn{8}{|l|}{ Others species } \\
\hline B. mycoides DSM 2048 & $\mathrm{C}$ & + & + & + & $7-\mathrm{D} / \mathrm{E}$ & + & + \\
\hline B. weihenstephanensis $\mathrm{KBAB} 4$ & $\mathrm{C}$ & + & + & + & 7-D/E & + & + \\
\hline Status of genome sequencing(GS): & & & & & & & \\
\hline
\end{tabular}

${ }^{2}$ NF: Not Found, TCT?: truncated ?, 7-D/E: prediction of amino acid residue incorporated by module 7 is D/E instead of Q, 6-X: no possible prediction for amino acid residue incorporated by module 6

$365+$ : protein present with at least $90 \%$ identity with the reference one, - : not present 


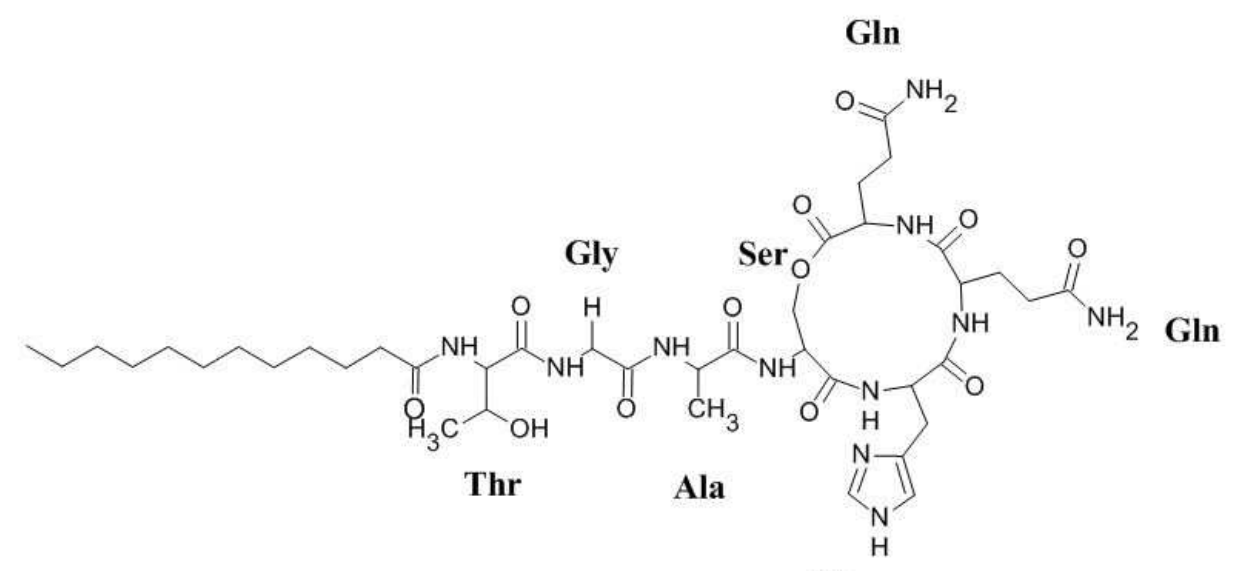

$366 I$.

His

367

$368 I I$.

370 369FA_Thr-Gly-Ala-Ser-His-Gln-Gln

$371 \mathbf{i C}_{11}$

$372 \mathbf{C}_{12}$

891.481

$373 \mathbf{C}_{12}[-\mathbf{O H}(3)] \quad 907.476$

$374 \mathrm{iC}_{12}$

891.481

905.496

$376 \mathbf{i C}_{13}[-\mathbf{O H}(3)] 921.491$

$377 \mathbf{C}_{14}[-\mathbf{O H}(3)] \quad 935.507$

378

A
FA Thr-Gly-Ala-Ser-His-Gln-Gln

n.r.

n.r.

n.r.

n.r.

939.502

953.518

B

379Fig. 1 I. Chemical structure of cyclic kurstakin with a C12 fatty acid chain. II. Structures and 380calculated molecular masses (Da) of the different isoforms of kurstakins characterized until 381now by MALDI-TOF-MS. A. Partially cyclic molecules (Hathout et al. 2000; Bumpus et al. 3822009); the square brackets [-OH(3)] in bold correspond to the presence of a $\beta$-hydroxylated 383fatty acid; B. Linear molecules (Bumpus et al. 2009). The amino acids Thr and Gln (in 384position 6) are expected to be under the D- form (Abderrahmani et al. 2011) (It is worthy of 
385note that L- and D- forms have never been chemically determined). The first kurstakin 386homologues, chemically characterized by Hathout et al. (2000), did not contain a $\beta$ 387 hydroxylated fatty acid, and comprised the sole $i \mathrm{C}_{11^{-}}, i \mathrm{C}_{12^{-}}$and $i \mathrm{C}_{13}$ isoforms isolated so far. 388FA = fatty acid; n.r. $=$ not reported to date 


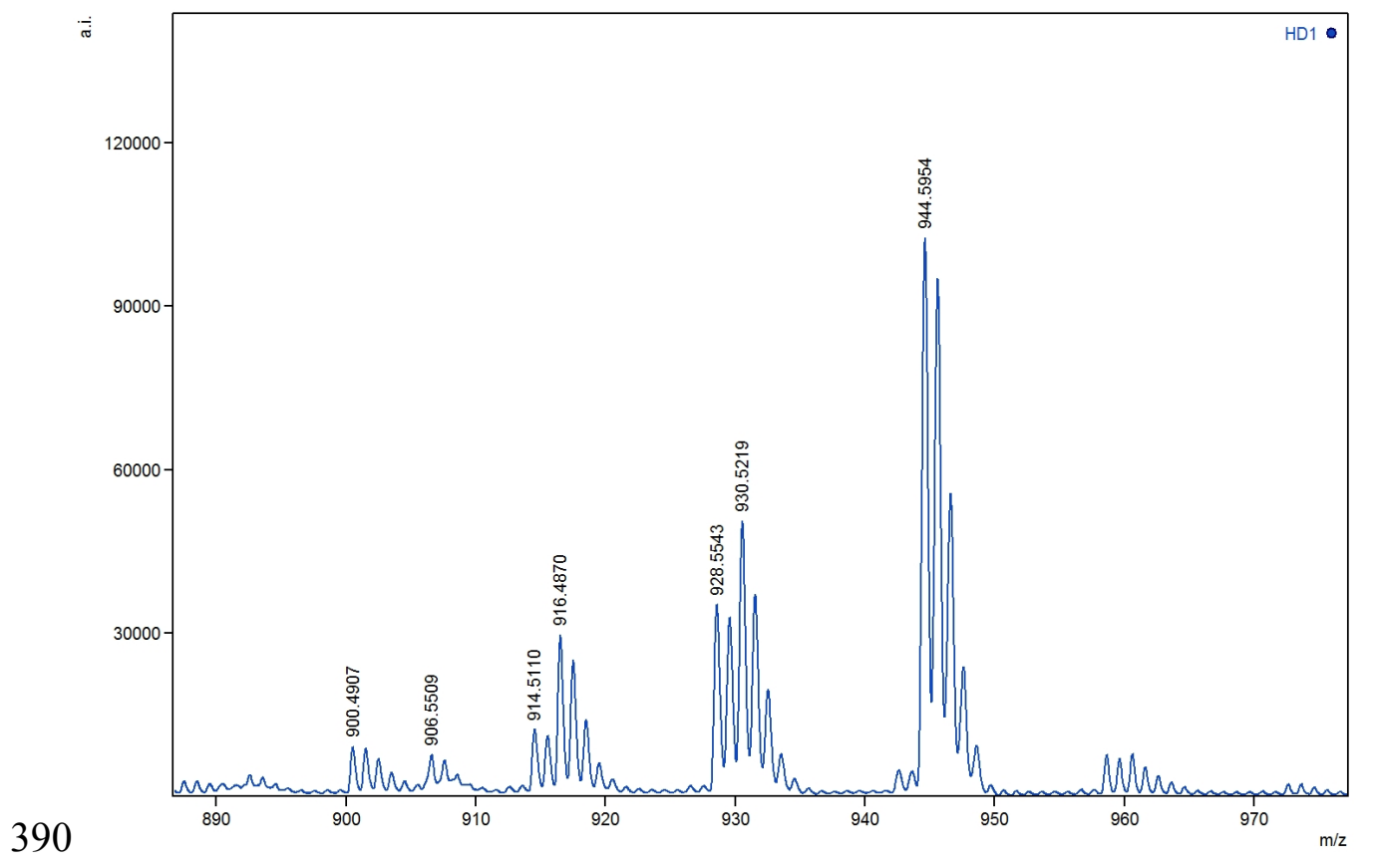

391Fig. 2 Typical pattern of whole cell MALDI-TOF MS analysis of the kurstakin producing 392strain B. thuringiensis subsp. kurstaki HD-1 (Caradec et al., unpublished data).

393Cyclic isoform with $\mathrm{C}_{11}$ fatty acid chain: $900.4907[\mathrm{M}+\mathrm{Na}]^{+}$; $916.4870[\mathrm{M}+\mathrm{K}]^{+}$

394Cyclic isoform with $\mathrm{C}_{12}$ fatty acid chain: $914.5110[\mathrm{M}+\mathrm{Na}]^{+}$; $930.5219[\mathrm{M}+\mathrm{K}]^{+}$

395Cyclic isoform with $\mathrm{C}_{13}$ fatty acid chain: $906.5509[\mathrm{M}+\mathrm{H}]^{+} ; 928.5543[\mathrm{M}+\mathrm{Na}]^{+} ; 944.5944$ $396[\mathrm{M}+\mathrm{K}]^{+}$ 

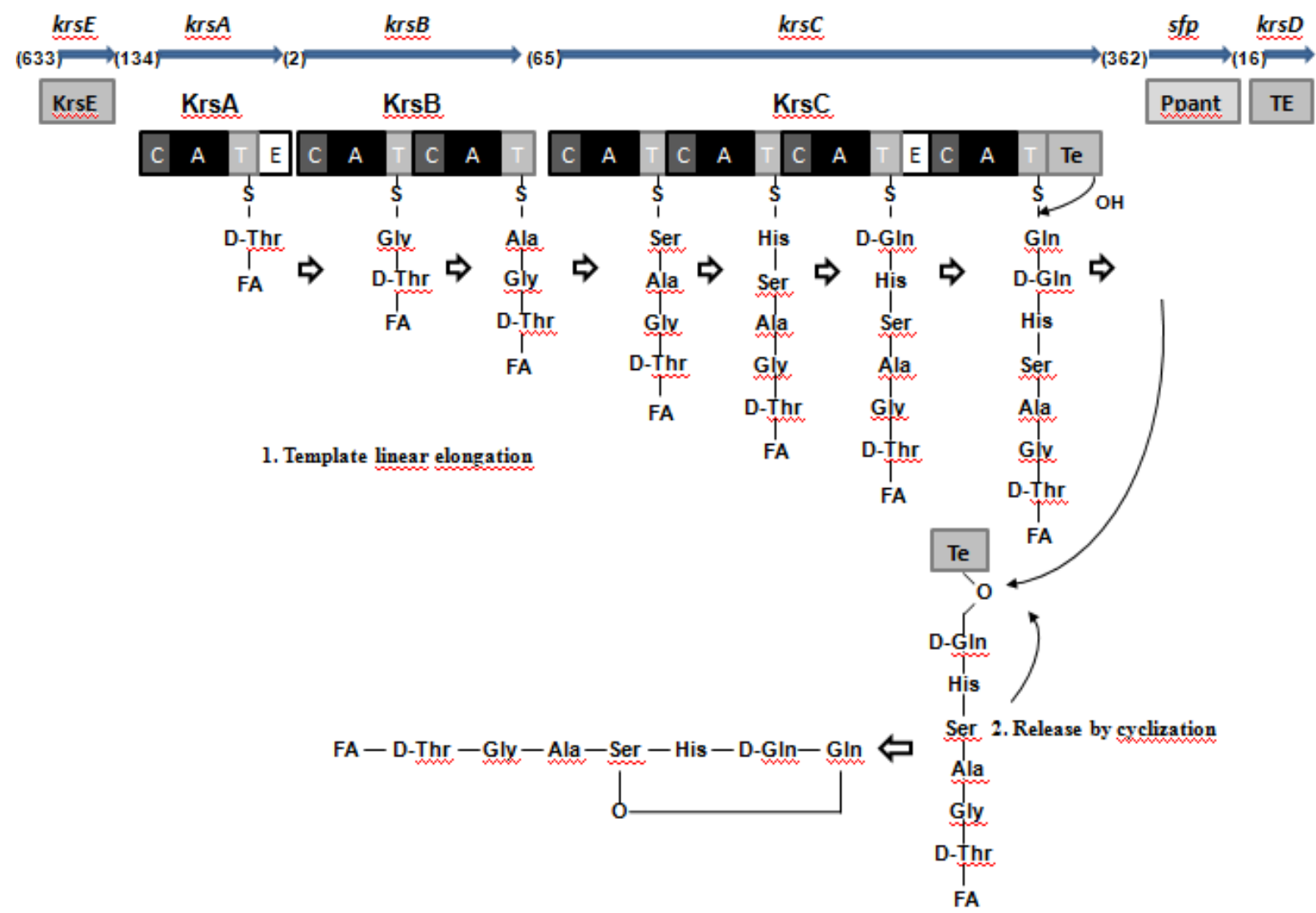

398

399Fig. 3 Hypothetical kurstakin biosynthetic assembly line based on bioinformatics analysis

400Situated downstream from the putative $k r s E$ gene which potentially encodes for an efflux 401protein which could be involved in the kurstakin secretion (bthur0010_59510), the 402biosynthetic complex consists of three kurstakin synthetases: KrsA, KrsB and KrsC (encoded 403by three genes: bthur0010_59520, bthur0010_59530 bthur0010_59540 in Bacillus 404thuringiensis serovar pondicheriensis BSCG 4BA1), divided into seven distinct modules. 405Each module is responsible for recognition, activation and loading of a single amino acid 406substrate. In the first module, a starter condensation domain links a fatty acid chain to the 407amino acid residue (Thr) activated and fixed in this module. Two epimerization domains are 408 found in modules 1 and 6, converting the corresponding amino acid in the D-stereoisomer. 409The cyclization and release of the final heptapeptide is catalyzed by the first adjacent Te 
410domain. Immediately downstream are situated two genes, coding for a phosphopantetheinyl 411transferase (bthur0010_59550) and a closely adjacent type II thioesterase (bthur0010_59560), 412 which are expected to belong to the kurstakin cluster. The numbers in brackets correspond to 413the spaces (in nucleotides) between these different open reading frames borne by strain BSCG 4144BA1. C: Condensation domain; A: Adenylation domain; T: Thiolation domain; E: 415Epimerization domain; Te: Thioesterase domain; Ppant: Phosphopantetheinyl transferase 416(Sfp); TE: Type II thioesterase; FA: Fatty acid 


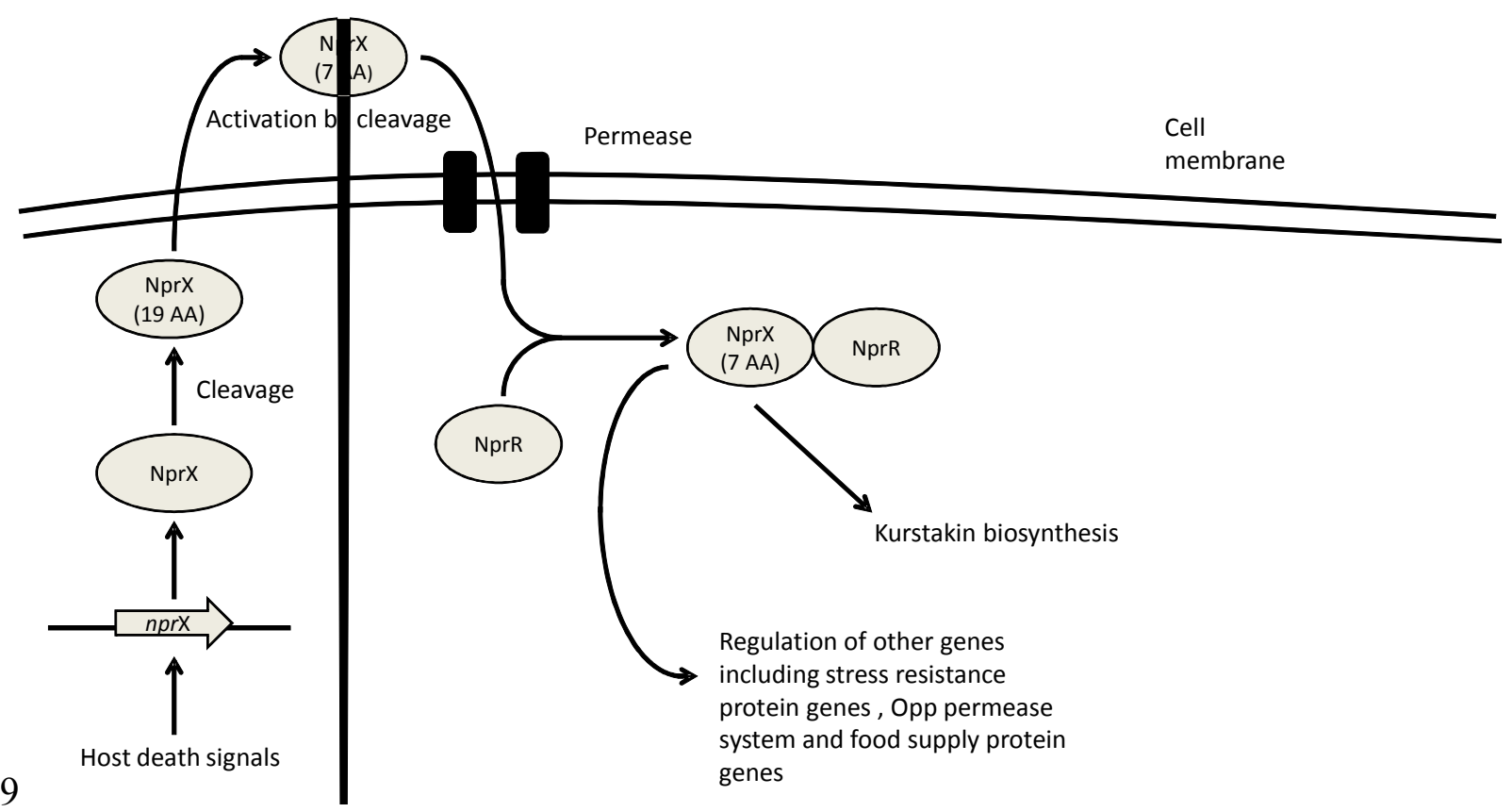

420Fig. 4 Regulation of kurstakin biosynthesis

421The NprX peptide is produced as an inactive form and is then activated by two successive 422cleavages. The first cleavage happens in the cell cytoplasm, and leads to a 19 amino acid 423peptide formation. After this first cleavage, the peptide is exported out of the cell, and is 424cleaved a second time in a 7 amino acids peptide, leading to its active form NprX. This 425peptide is then reimported within the bacterial cell through the Opp permease system, and is 426bound with the NprR regulator. NprR forms a complex with the heptapeptide NprX whose 427production is regulated by host-death signals. The NprX-NprR complex activates the 428kurstakin production, by binding to the -35 box of the promoter of the $k r s$ genes (Perchat et al. 4292011). 